Article

\title{
Linking Material Flow Analysis with Resilience Using Rice: A Case Study in Global, Visual MFA of a Key Food Product
}

\author{
Michal Monit *, André Pina and Paulo Ferrão
}

Received: 5 November 2015; Accepted: 6 January 2016; Published: 20 January 2016

Academic Editor: Witold-Roger Poganietz

IN+, Center for Innovation, Technology and Policy Research, Instituto Superior Técnico, Universidade de Lisboa, Av. Rovisco Pais, 1, Lisboa 1049-001, Portugal; andre.pina@tecnico.ulisboa.pt (A.P.); ferrao@tecnico.ulisboa.pt (P.F.)

* Correspondence: michal.monit@singularityu.org

\begin{abstract}
This article uses the rice price crisis of 2007-2008 to show how material flow analysis (MFA) can be combined with resilience research. After presentation of fundamental information and methods, resilience-related concepts are illustrated using graphical methods and MFA data. Herfindahl-Hirschman Index (HHI) and node-link diagrams are used to highlight potential vulnerability hotspots and show response to, recovery from disturbance and adaptation following a disruption of the global rice market. The methods presented are especially useful in rapid screening for potential impact of supply-side disruptions, such as export restrictions or poor harvests. The article concludes by discussing other potential applications of the chosen approach and stressing the importance of visual communication in dissemination of results and cross-pollination between disciplines. All the data used in this study is available online, as interactive visualizations, at: http:/ / ricestudyvis.weebly.com.
\end{abstract}

Keywords: material flow analysis; material flow accounting; rice; crisis; food network; resilience; vulnerability; adaptation; visualization; mapping

\section{Introduction}

Official trade statistics for 2012 (see Section 2.1) reported that 82 countries produced rice while trade in rice occurred between 1655 pairs of partners. This is not a number easy to fit in a single table or process quickly by a busy decision-maker. Graphical methods and interactive queries provide an alternative; and some ways to quickly sort, filter, and understand the data.

From a different perspective, instead of separate points in a table, treating the data as a system-with links, nodes, and underlying conditions-allows us to go beyond accounting perspective and bridge information and understanding between adjacent, yet discrete, fields.

Both points of view will be illustrated in this article through a case study revolving around the rice price crisis.

\subsection{The Rice Crisis}

The 2007-2008 rice crisis, in all likelihood, was not a result of a physical shortage, but rather global speculation and policy measures undertaken by the three major rice exporters-India, Vietnam, and Thailand; as well as the actions undertaken by Philippines—-the biggest importer [1]. This caused a sudden hike in prices of rice and defaults on agreed deliveries, on top of a number of ongoing global disturbances, including oil price shock, escalating credit crisis, and concerns of poor harvest in Asia. 
The resulting situation affected Asian markets severely, but even more so some of the poorest nations relying on imported rice as a major source of staple food, primarily in West Africa [2].

\subsection{Material Flow Accounting and Analysis}

The original focus of material flow accounting (MFA, see Appendix A) lay in linking economic welfare and physical throughput of economy [3]. MFA as a distinct field of study which emerged rather recently [4] and gained popularity after Eurostat took the brunt of the work towards consolidation of the methodology [5]. Therefore, the standardized methodology of economy-wide material flow accounts (EW-MFA) became one of the most recognized approaches among the methods used in material flow analysis at the country level. Currently, the economy-wide material flow accounts is considered a fairly mature and robust approach [6] and countries in the European Union are mandated to report material consumption indicators, following the compilation guide published by Eurostat [7].

However, biggest potential contributions of material flow analyses had been linked to its ease of incorporating diverse spatial and temporal scales [8]. This could have enabled material and energy flow analysis (MEFA) to become a methodology of choice for monitoring progress towards sustainability [9], but arguably, material flow analysis is still effectively restricted to accounting material use, as pointed out in the very same publication from over a decade ago [9].

\subsection{Resilience, Vulnerability, and Adaptation}

Resilience, vulnerability, and adaptation (RVA) are three related fields which had been developing in relative separation [10] due to their disparate roots, but all revolve around the ability of systems to overcome external (or internal) disturbances.

Emergence of resilience as a field is usually linked with the work of Holling [11]. His later work [12] clearly distinguished between the engineering and ecological resiliencies. Engineering resilience is tied with the ability of a system to rebound and "spring back" [13] to its previous state, and the speed at which it happens. The ecological resilience, on the other hand, describes propensity to maintain original function in the face of disturbance. In real-life systems, those two types of resilience have to be balanced to maximize the odds that the system will last (cf. Figure 1), despite all the internal and external perturbations and disruptions.

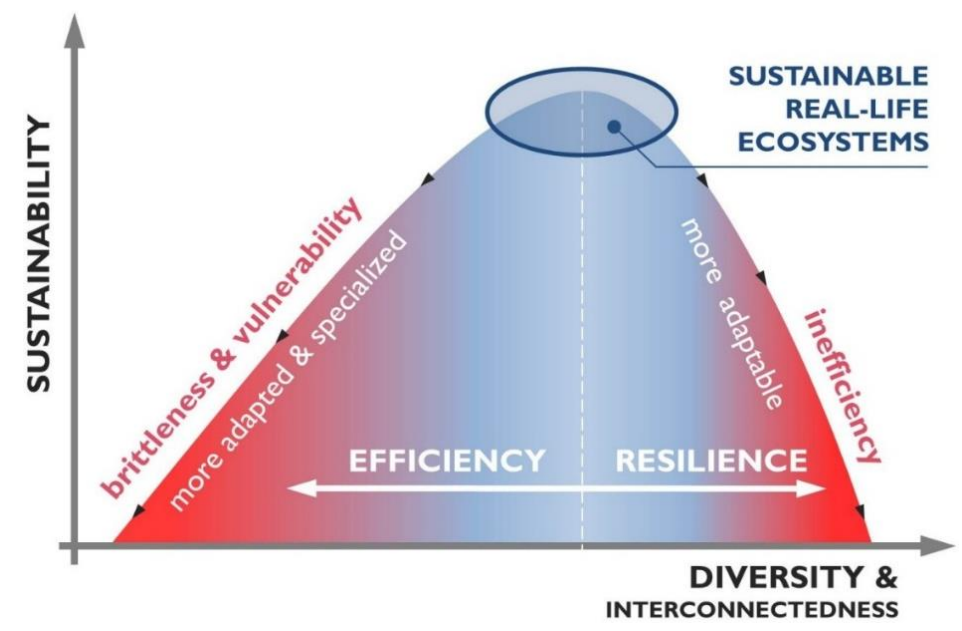

Figure 1. Trade-offs between sustainability and diversity. Adapted from: The Ellen MacArthur Foundation [14].

Zhu and Ruth [15] study resilience and efficiency of industrial ecosystems using simulated network models. They find that diversity of supply can have different effects on local and global scales, however in most cases high diversity of supply reduces risk exposure of a firm, but often 
leads to erosion of profits. On the other hand, the most dangerous disruptions propagate from highly connected firms. Additionally, the study concludes that high dependency not only decreases resilience directly, but also allows the disruptions to propagate further. A different study [16] finds that interdependent networks are more fragile, which agrees with the statement that the rice price crisis was either aggravated or happened in large part because of all the tribulations of 2008.

Vulnerability is often described as susceptibility to harm [17], but depending on research agenda, the term does not have a universally agreed definition [18]. The origins of vulnerability research are tied to the context of natural disasters [10], but nowadays also include factors spanning from poverty to climate variability. Out of the RVA triplet, vulnerability is the one most often tackled using graphical and visual approaches, which facilitates directing attention and political action towards phenomena such as climate change vulnerability [19]. It is important to note that the growth in software, computing, and visualization has enabled construction of interactive tools which allow non-experts to tap into locally-relevant information [20,21].

Adaptation might be the most dated concept out of the RVA triplet, as interest in the topic is traced back to anthropologists in the early 20th century [10]. Therefore, less focus was put on mathematical models and more on the mechanisms of adjustments enabling continuation on a stable development trajectory [22]. As such, adaptability is sometimes treated as part of (engineering) resilience and when sustainability necessitates changing to a new stable state (ecological resilience), the quality is referred to as transformability. The confluence of resilience, vulnerability, and adaptation is discussed in detail by Gallopin [18].

\section{Methods and Data}

\subsection{System Definition and Data}

This study follows the most basic nomenclature used in EW-MFA, illustrated in Figure 2. Domestic extraction (used) accounts for all the materials sourced and used internally within the economy. For calculations of indicators, only import data has been used to avoid asymmetry between reported import and export flows. Using DE (domestic extraction) and imports, one can calculate the inputs to the economy-domestic material inputs (DMI) and the level of reliance on imports, here noted as "self-sufficiency" and expressed as the ratio of domestic extraction to all the inputs (DMI).

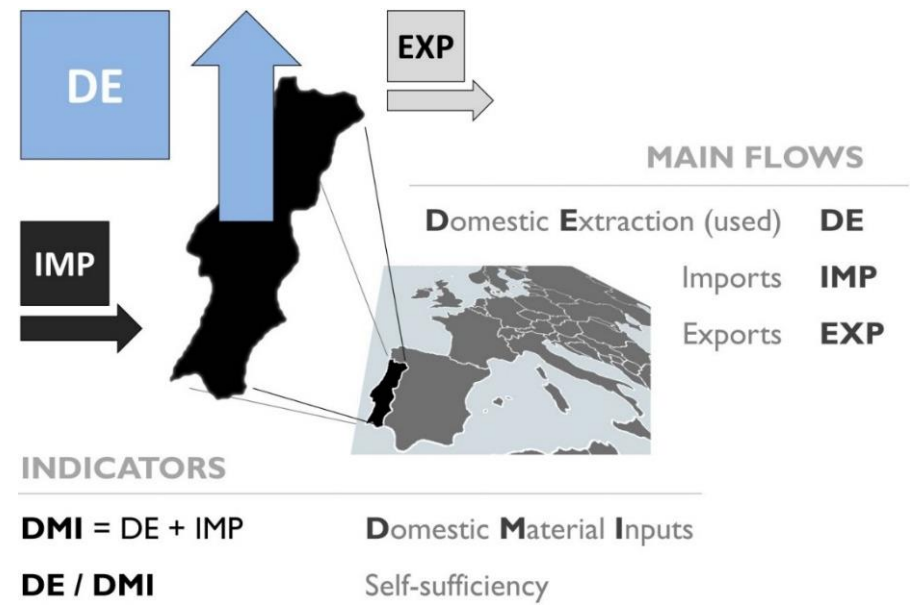

Figure 2. Basic EW-MFA flows and indicators used in this study-illustration.

All the data used in this study comes from two online sources. Data on domestic extraction of rice has been obtained from FAO (Food and Agriculture Organization of the United Nations), code: 5312 [23], while data on imports and exports has been downloaded through an API call from United Nations' Comtrade website (Standard International Trade Classification (SITC), Revision 3 
code: 042) [24]. The time periods chosen for the analysis are: 1992, 1997, 2002, 2007, 2008, 2009, and 2012 (five-year intervals, all originally reported in SITC, Revision 3 and two additional years-2008 and 2009, to capture the effects of the "rice crisis").

Countries' extraction and trade data have been combined through (adjusted) three-letter ISO3 (International Organization for Standardization 3166-1 alpha-3 country codes) correspondence. In cases where trade data from UN Comtrade was missing weight (but had monetary value), the values were inferred using global average unit price $(\$ / \mathrm{kg})$ calculations, following reference [25]. Data processing was done in R programming language [26] and visualizations made in Tableau Public 9.0 (Tableau Software, Seattle, WA, USA).

\subsection{HHI and Node-Link Diagrams}

Herfindahl-Hirschman Index (HHI) is a measure of concentration of markets, widely applied to issues regarding market concentration and monopolies. In this study, it will serve as a proxy of diversity, and concentration, of either supply or imports. HHI can by calculated by summing squared shares of all the market participants. If expressed in terms of production of each market participant $\left(x_{i}\right)$, the index can be calculated as follows:

$$
H H I=\sum\left(\frac{x_{i}}{\sum x_{i}}\right)^{2}
$$

Hence, the index can take values between 0.0 (perfect competition) and 1.0 (single monopoly) and for markets with $\mathrm{N}$ players with equal market shares, HHI simplifies to $1 / \mathrm{N}$. Antitrust guidelines suggest two important reference points for classification of market concentrations-HHI values of 0.15 and 0.25 , with:

- competitive and "diluted" markets: $\mathrm{HHI}<0.15$;

- moderately concentrated markets: $0.15<\mathrm{HHI}<0.25$;

- highly concentrated markets: $0.25<$ HHI.

HHI index can have the same value for different market (or supply) structures, as shown in Figure 3.
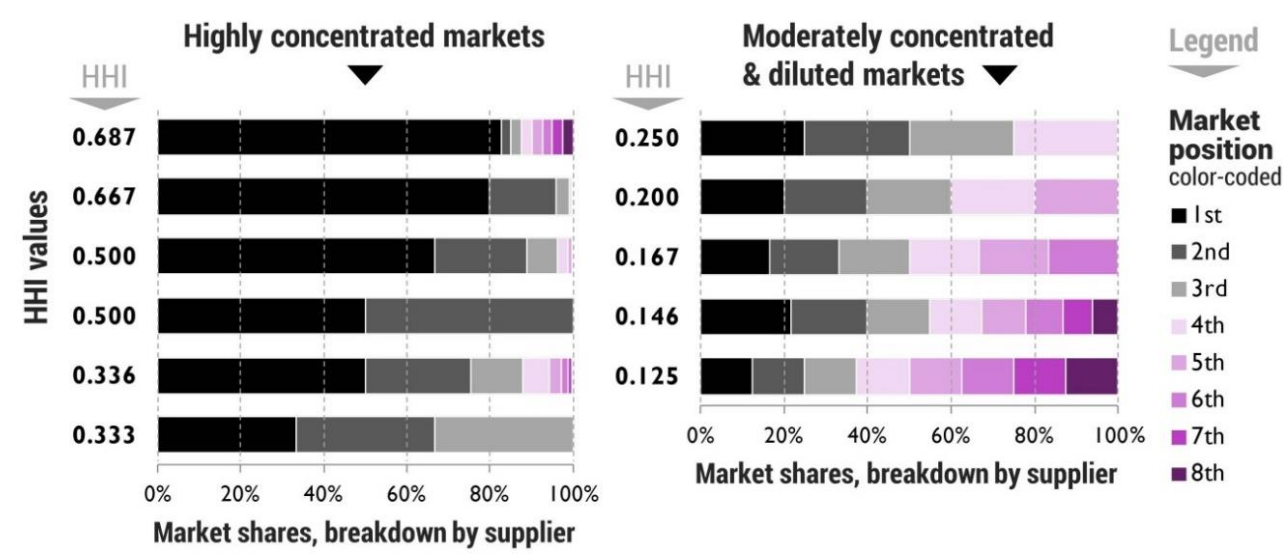

Figure 3. Various market structures and their corresponding HHIs.

Node-link diagrams are used to illustrate the global network of rice supply and consumption. It allows the graphing of a number of qualities in a single diagram (see Figure 4), i.e., size (DMI) and self-sufficiency of national markets as nodes as well as diversity and volume of imports as links between the nodes. Clear coloring scheme allows easy screening for, and identification of, potentially vulnerable spots in the network, whereas interactive form allows querying for additional information. 
Fully interactive versions of Figure 4 (and other) diagram(s) are available online at: http:/ / ricestudyvis.weebly.com (see Appendix B).

\section{LINKS}

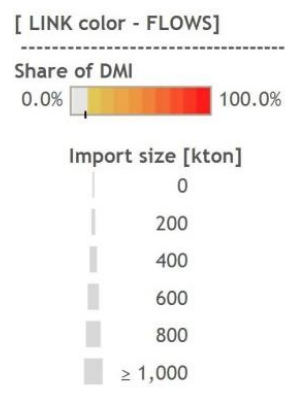

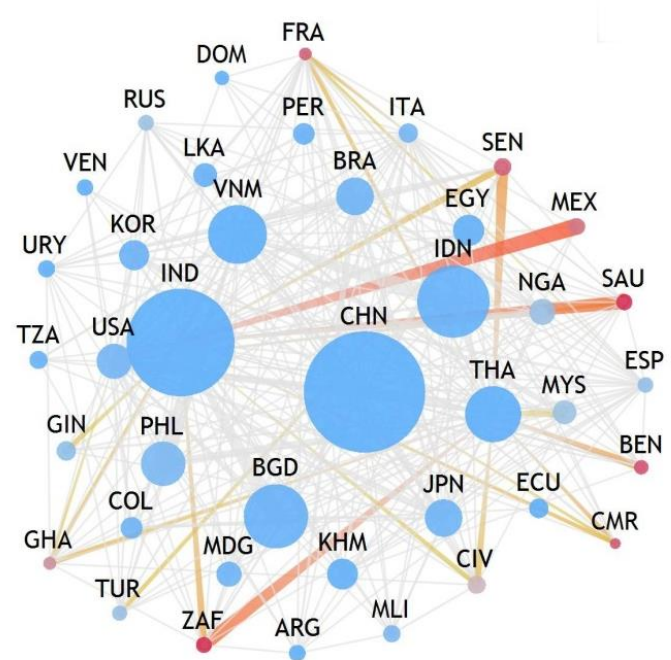

Filters: $\quad$ Year $=2007 ; \quad$ DMI $>500$ kton; $\quad$ Import $>10$ kton

\section{NODES}

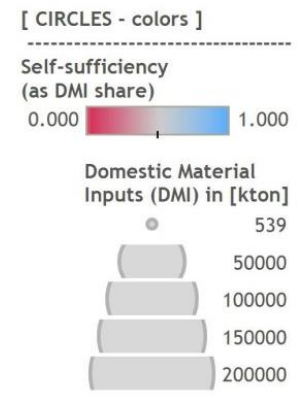

Figure 4. Example of simplified node-link diagram visualization for global rice trade network in 2007. Each node depicts a single country (three-letter, ISO3 code label) with the size of the circle corresponding with the magnitude of DMI. Each line illustrates a trade relationship reported between two countries. The thicker end links to the country which imports more. Both nodes and links are color-coded using red and orange hues to pinpoint potentially vulnerable spots in the global market.

\section{Results and Discussion}

Aggregated results (provided in the table below) show steady growth in demand for rice, levelling off around 2008. Year 2002 is a clear outlier, which is a result of erroneous entries (more information provided in Appendix C). The global structure of supply seems to be relatively stable. Few major producers dominate both the supply and consumption of rice while international trade flows play only a minor role, globally.

Table 1. Aggregated, world-wide data related to rice, based on information from FAO. DE-global domestic extraction, equal to global production, IMP-global sum of imports, unit price is expressed in nominal dollars, based on global trade value and volume. Flows missing weight data, but having monetary values, have had weight assigned based on global average price for a given year as in reference [25].

\begin{tabular}{ccccccc}
\hline Year & $\mathbf{N}$ & DE (kton) & IMP (kton) & Unit Price $\mathbf{( \$ / k g )}$ & Missing Weight $\mathbf{( \%}$ of Value) & Added Weight (\%) \\
\hline 1992 & 86 & 477,146 & 4628 & 0.431 & 1.37 & 1.39 \\
1997 & 139 & 548,063 & 10,527 & 0.423 & 1.62 & 1.65 \\
2002 & 154 & 569,357 & 36,813 & 0.155 & 0.62 & 0.62 \\
2007 & 161 & 624,406 & 21,509 & 0.450 & 0.08 & 0.08 \\
2008 & 163 & 649,975 & 20,868 & 0.713 & 0.00 & 0.00 \\
2009 & 160 & 646,621 & 18,279 & 0.670 & 3.51 & 3.64 \\
2012 & 166 & 652,255 & 22,709 & 0.686 & 0.38 & 0.38 \\
\hline
\end{tabular}

\subsection{Modes of Vulnerability}

The trade flows of countries can be broken down into a number of different groups, based on the level of diversification of their rice imports (expressed as HHI of imports) and level of self-sufficiency 
of their own production (share of imports and HHI of DMI). One such breakdown, which could be useful for screening for vulnerabilities, is represented graphically in the following diagram (Figure 5).

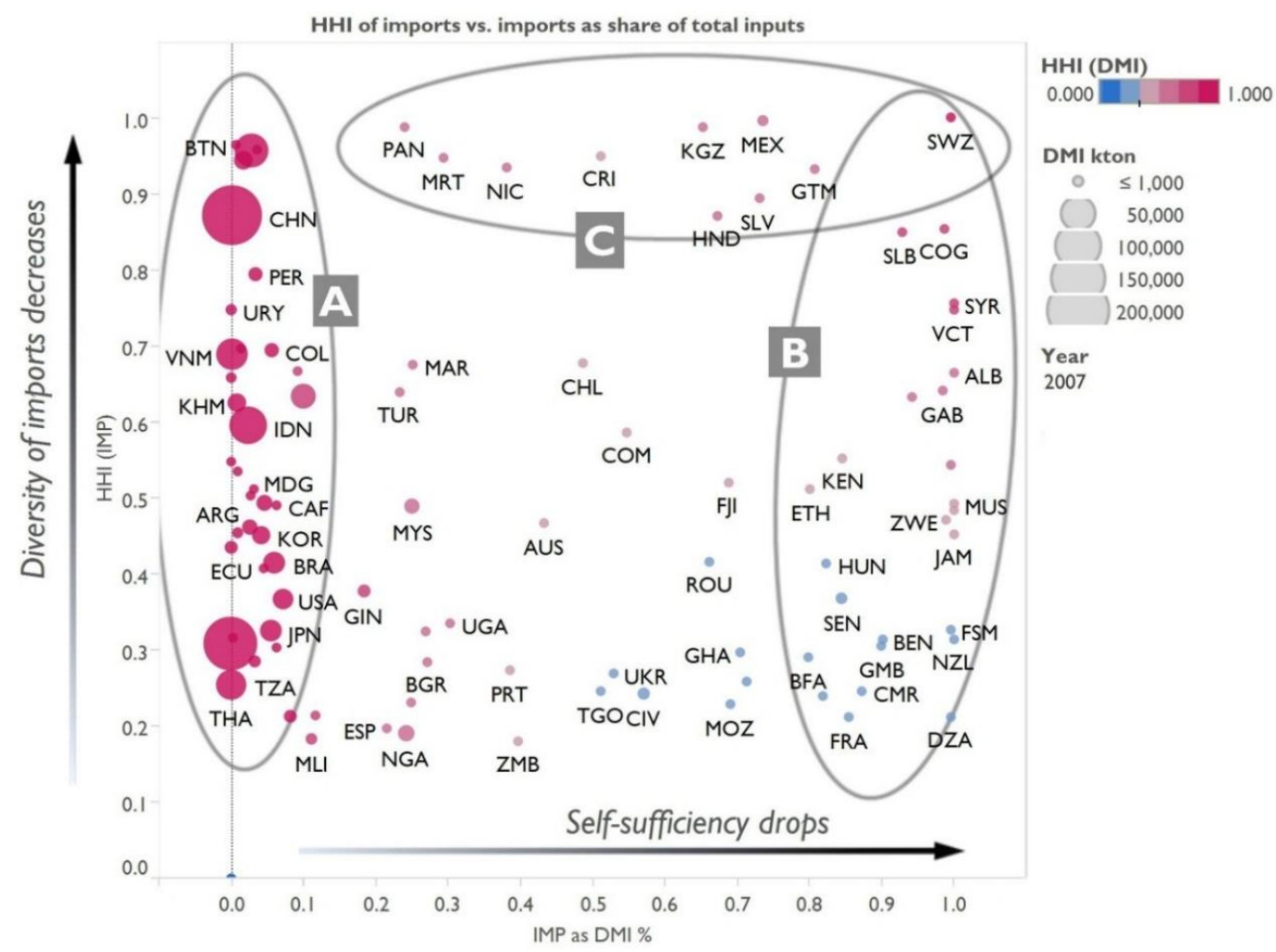

Figure 5. Grouping countries according to self-sufficiency (DE/DMI) and diversification of imports [HHI(IMP)] reveals potential vulnerability modes. (A) Major producers and consumers, which may not be able to cover potential shortages from the global trade market; (B) countries completely reliant on imports of rice; $(\mathbf{C})$ countries reliant on a single importer, providing various shares of overall rice inputs (DMI).

Virtually all major players have high self-sufficiency (A), with varying levels of diversification of imports, which in their case constitute only a minor share of overall inputs (DMI). On the opposite side (B) are the countries which rely almost entirely on imports for provision of rice. There are also a few countries which have basically a single source of rice imports (C). All of those groups have different problems related to the resilience of their supply of rice. Group A is self-reliant, however, taking into account the sheer size of consumption in this group, any country-level poor harvest can result in shortages exceedingly difficult to cover with international trade (which is very small compared with global consumption). Group $C$ is vulnerable, because it is virtually completely reliant on a single provider for all of their imports (of rice), whereas in the group B this type of risk is distributed among a varying number of trade partners.

The next, node-link diagram (see Appendix D) (Figure 6) illustrates how to easily identify potential hotspots in the rice consumption and trade network. In 2007, Congo (COG) imported all of its rice from basically a single source and produced close to none. The trade partner was Thailand. For Gabon (GAB) the situation was similar, but a significant share of imports came from Vietnam. In 2008, both rice exporters introduced export restrictions. Both countries importing rice (GAB, COG) were left with their main supply lines suddenly cut, aggravated by the fact that their purchasing power and ability to tolerate high prices was low due to low income. Mexico (MEX) was in a different situation; it relies almost completely on the US for provision of rice. Were rice production in the US to collapse, it would be almost a surefire sign of a major trouble for the Mexican food market. 
Interactive versions of the link-node diagrams can be found at: http:/ / ricestudyvis.weebly.com (visualization 2).

\section{Potential risks in red hues}

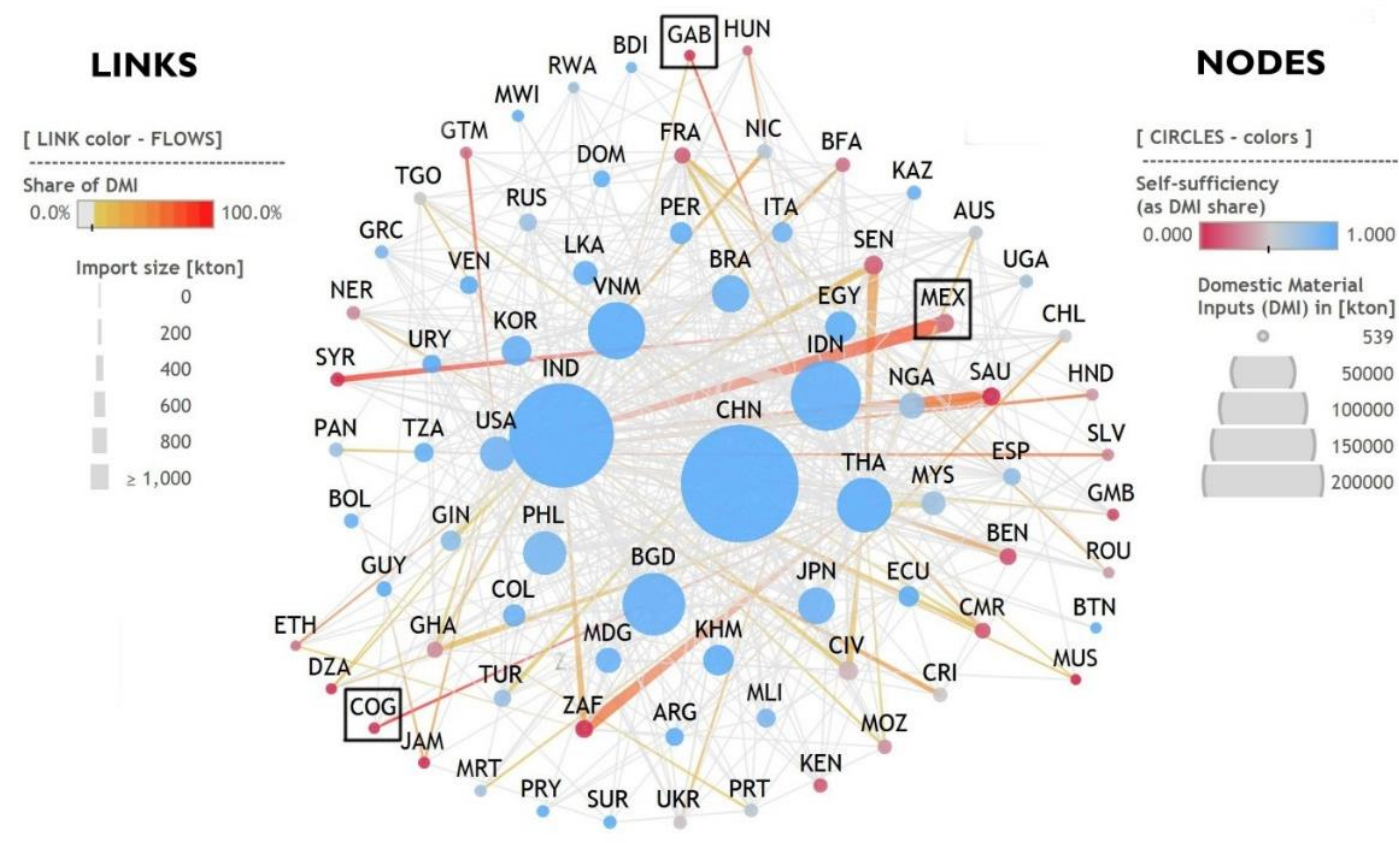

Filters: $\quad$ Year = 2007; $\quad$ DMI > 500 kton; IMP > I 0 kton

Figure 6. Using node-link representation to simultaneously visualize both production and trade of rice around the world. Nodes are color-coded according to their level of self-sufficiency and sized according to overall inputs (DMI). Each link represents a bilateral trade relationship between the countries. Ends of the lines are sized according to the size of import and colored according to how big a share this trade flow constitutes $\left(\mathrm{IMP}_{\mathrm{i}} / \mathrm{DMI}\right)$.

\subsection{Shock, Resilience, and Adaptation Strategies}

Graphical methods offer simple heuristics to identify crises, such as the 2007-2008 rice price crisis. Figure 7A shows diversification of rice imports_-HHI(IMP)—over time and features major reshuffling of time series in 2008-suggesting occurrence of a sudden, impactful event. Historically, major importers (depicted with thicker lines) seemed to consolidate their imports between 2002 and 2007 (HHI going up). Then, in 2008, a major disruption occurred, followed by data rebounding in 2009 to values similar to 2007. After that, major importers followed a fairly uniform trend towards diversification of their imports (HHI going down by 2012). The last bit of information-most countries with major rice imports trying to split their imports among more countries (see Figure 7B)—is even more interesting, considering that all four of the biggest producers decrease their $\mathrm{HHI}$, despite the fact the imports are only a minor fraction of their overall demand for rice and are more of an option rather than necessity.

In the face of the crisis, not all countries were affected equally. That can also be interpreted using graphical explanations. First, it is important to note that most rice trade originates and occurs in South-East Asia (Figure 8A). It is the region where majority of rice is produced and traded. Because the rice crisis originated and escalated there, it was the Western African countries, which suffered most collateral damage. In large part, it was a result of heavy reliance on rice imports from that region shown through prevalence of red- and orange-colored trade links between Africa and Asia (Figure 8B). 

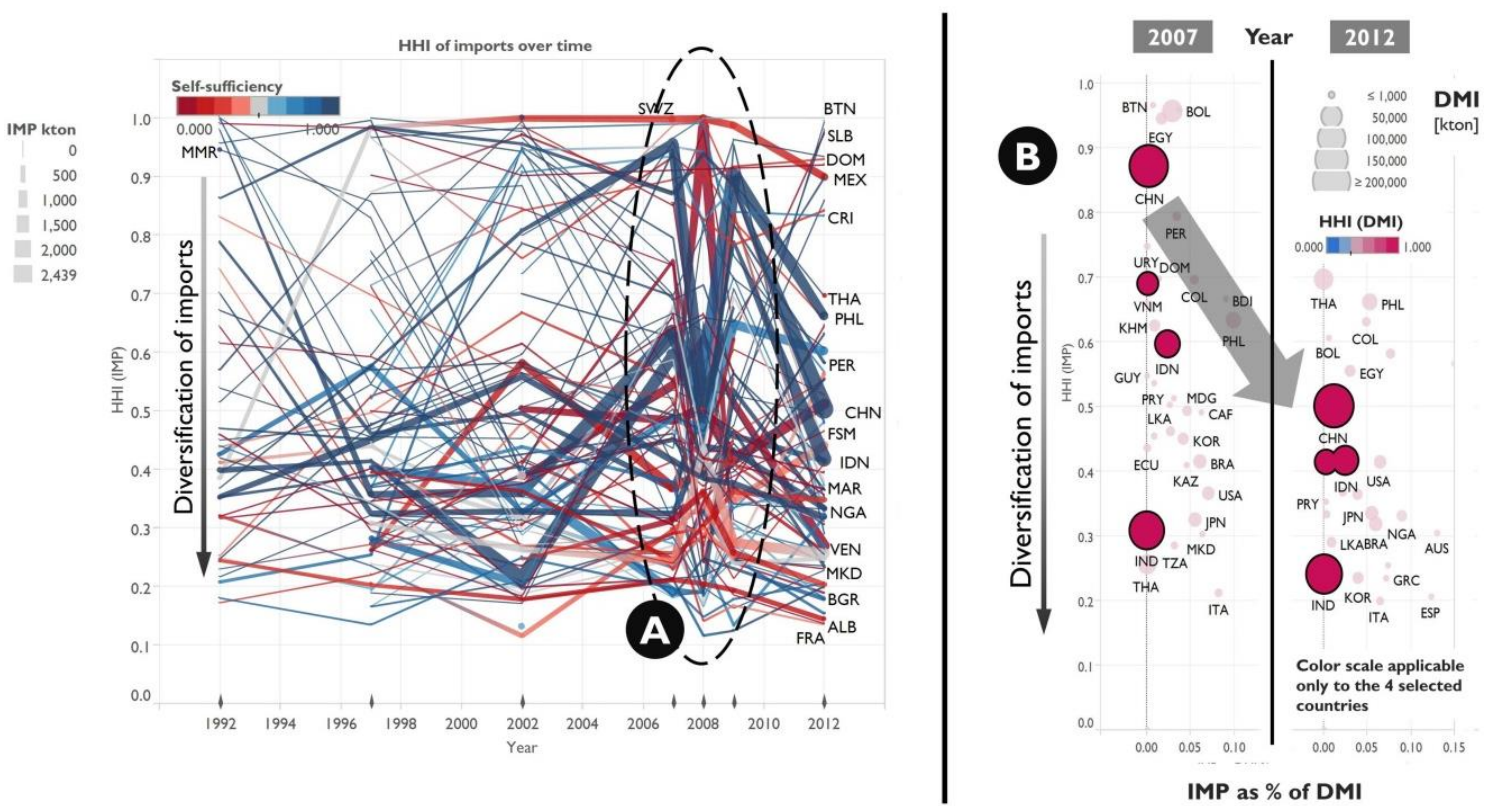

Figure 7. Changes in diversification of rice imports (HHI(DMI)) over time: (A) Around 2008, a sudden disruption and rebound of time series occurs, coinciding with the 2007-2008 rice price crisis; (B) Between 2007 and 2012, the four biggest rice producers uniformly increased the diversification of their rice imports. That occurs notwithstanding their share of imports is very small (IMP as \% of DMI) compared with the overall productive capacity.

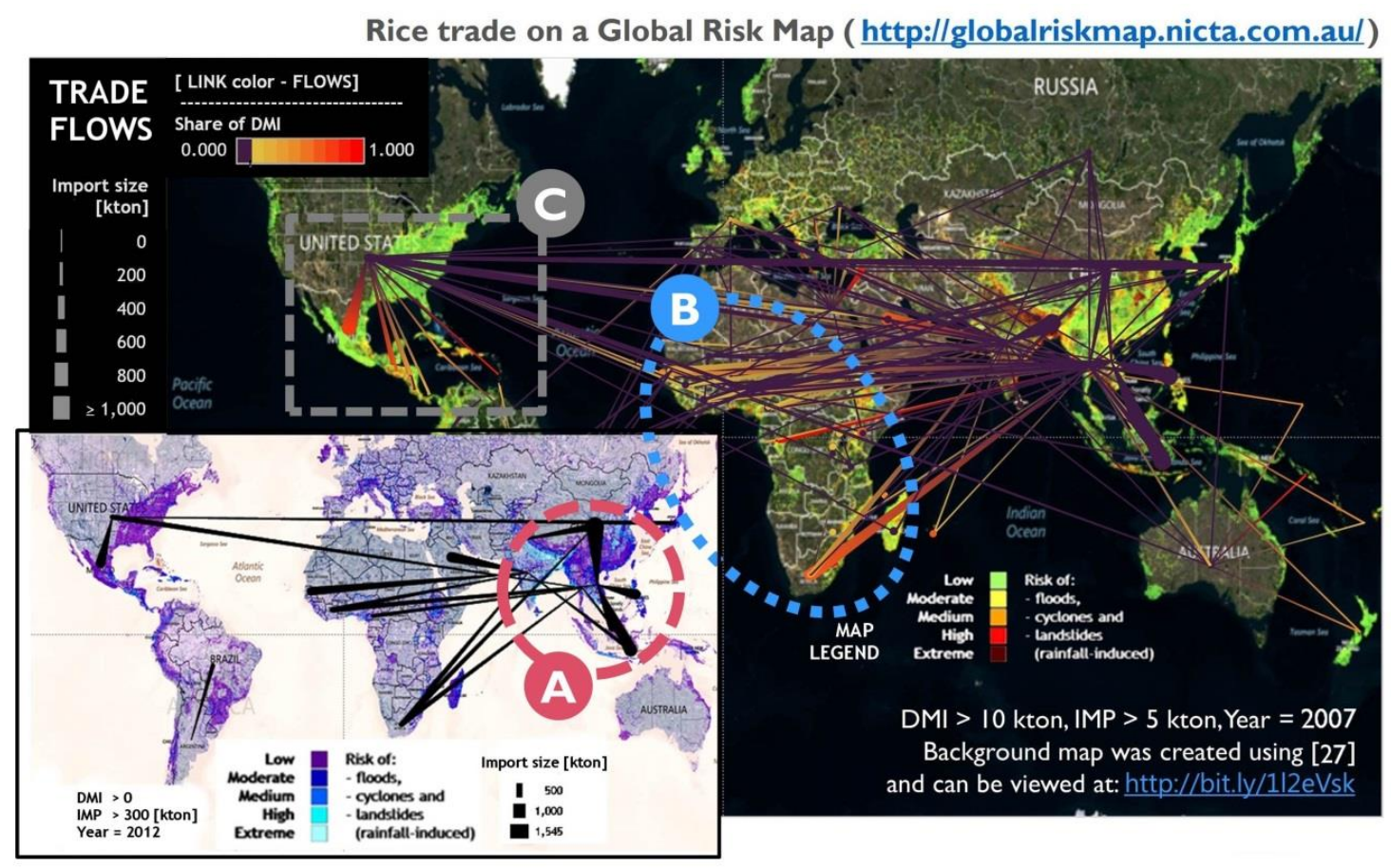

Figure 8. Trade relationships in rice overlaid over a world map. (A) The biggest trade volumes occur in Southeast Asia. That is also the region responsible for majority of exports; (B) Most of Africa, in particular the western part, has a high share of their rice inputs fulfilled by imports from SE Asia; (C) The US is a major rice producer in its region of the world. Most neighboring countries had been heavily reliant on imports from the US (trade links in orange and red, in 2007). 
A focus on a different part of the global map of rice trade (Figure 9) can explain why American nations did not suffer that badly through the 2007-2008 rice crisis. The US has completely dominated rice production in its region (Figure 8C). South American nations have been largely cut off from the crisis because of little need for imports and dominance of within-region rice trade (Figure 9). Therefore, because of their structure of rice trade and production, the American rice markets were buffered from the short-term price fluctuation originating in Asia. Hence, the resulting lack of effective price transmission mechanism [2] can be attributed with comparatively low impact on import prices, at least in South America (Figure 10).

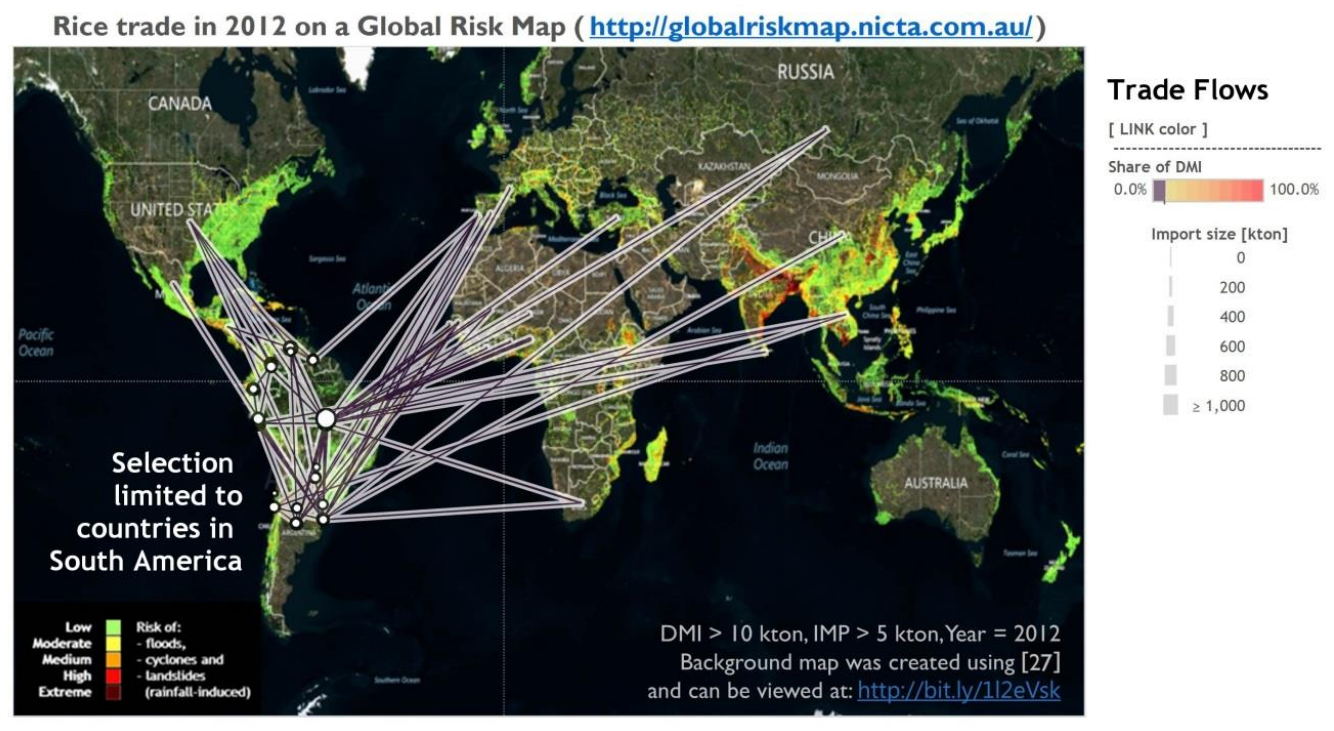

Figure 9. The South American rice market is fairly isolated. Most countries are self-sufficient (trade links in purple) and majority of trade occurs within the region. Background map created using [27].

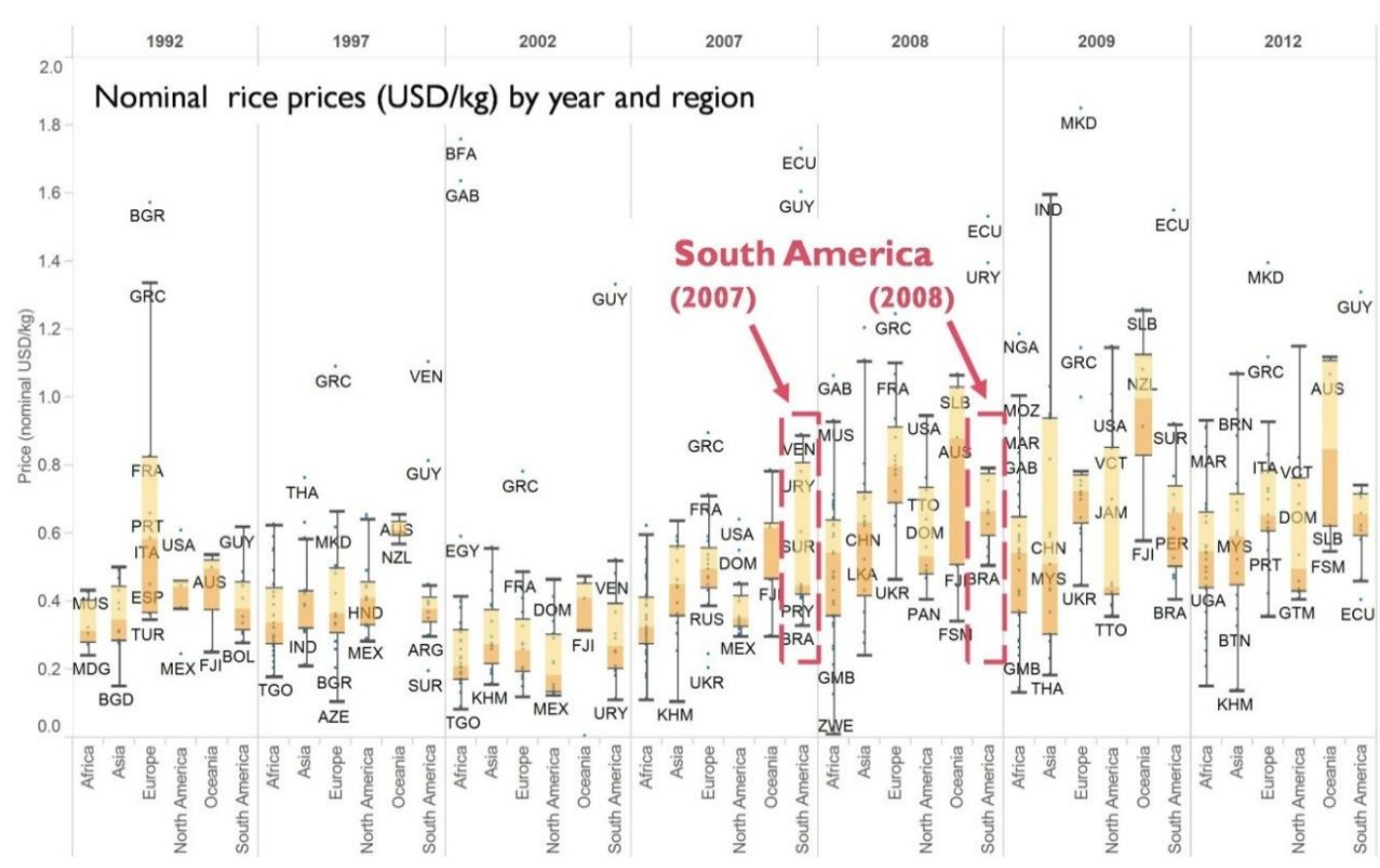

Figure 10. Nominal rice prices (USD/kg) of imports disaggregated by year and region. The changes in prices of South American imports (marked in carmine) were not as pronounced as that of other regions. Data: Own calculations based on UN Comtrade. 
On the other side of the impact spectrum of the rice crisis were most of the African nations-heavily reliant on imports, with diets featuring lots of rice and with little economic power to burden sudden price fluctuations. Still, even in this group there is no single story. First, it seems that the level of diversification has some impact on the type of reaction resulting from the crisis (Figure 11): highly diversified countries often increase HHI temporarily (most likely filling the gaps from a single, reliable source), whereas countries with high HHI often do the opposite (decrease HHI, because they need to find new partners which can fill in the demand when the major source of imports stumbles).

Mauritania (MRT) seems to belong to the latter group. Either because of conscious decisions or poor harvest it decreased its self-sufficiency around the time the crisis struck. The shock has been followed by rapid diversification of imports and buildup of national production. Senegal (SEN) and Gambia (GMB) reacted in a similar way-by increasing self-sufficiency. South Africa (ZAF) and Cote $\mathrm{d}^{\prime}$ Ivoire (CIV) behaved in a different fashion-both to keep on increasing the volume of imports and try to keep HHI of imports at a level lower than in 2008. Finally, Nigeria (NGA) could be considered a success story-the rice crisis of 2007-2008 either coincided with or became the reason for permanently reduced volume of imports along with a $\sim 20 \%$ increase in self-sufficiency which consistently exceeds $90 \%$, post-2008. The situation is depicted in the following diagram (Figure 11). The semi-transparent line showing a major increase in 2008 ( $Z W E$, Zimbabwe) is an example of erroneous data entries (cf. Appendix C).

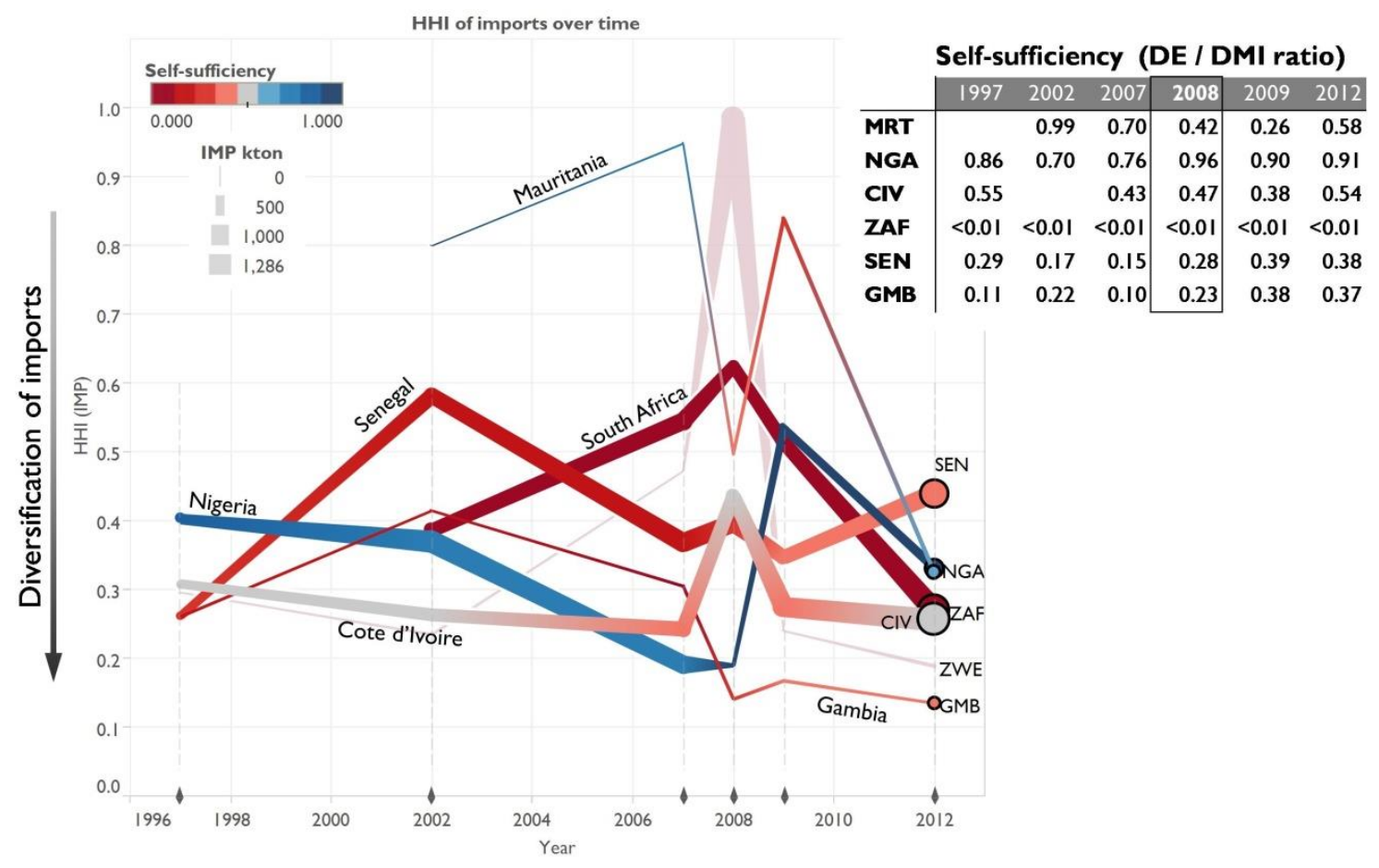

Figure 11. Diversification of imports of selected African nations illustrating different responses to and circumstances regarding the 2007-2008 rice price crisis.

Lastly, the relational approach to extraction and trade data can show us that not only the importers of rice have been affected. Post-2008, Thai rice exports became significantly smaller shares of rice imports of their partners, illustrated in the Figure 12, by decreasing amount of red hues between 2007 and 2012. This could be explained by the global market losing confidence in Thailand as it contributed to the rice crisis, but more importantly, featured a prominent politician mentioning in public that Thailand could initiate creation of a rice cartel, fixing prices, following the example of the oil-exporting countries [1]. 


\section{Node-link trade relationships for rice - focus on Thailand}
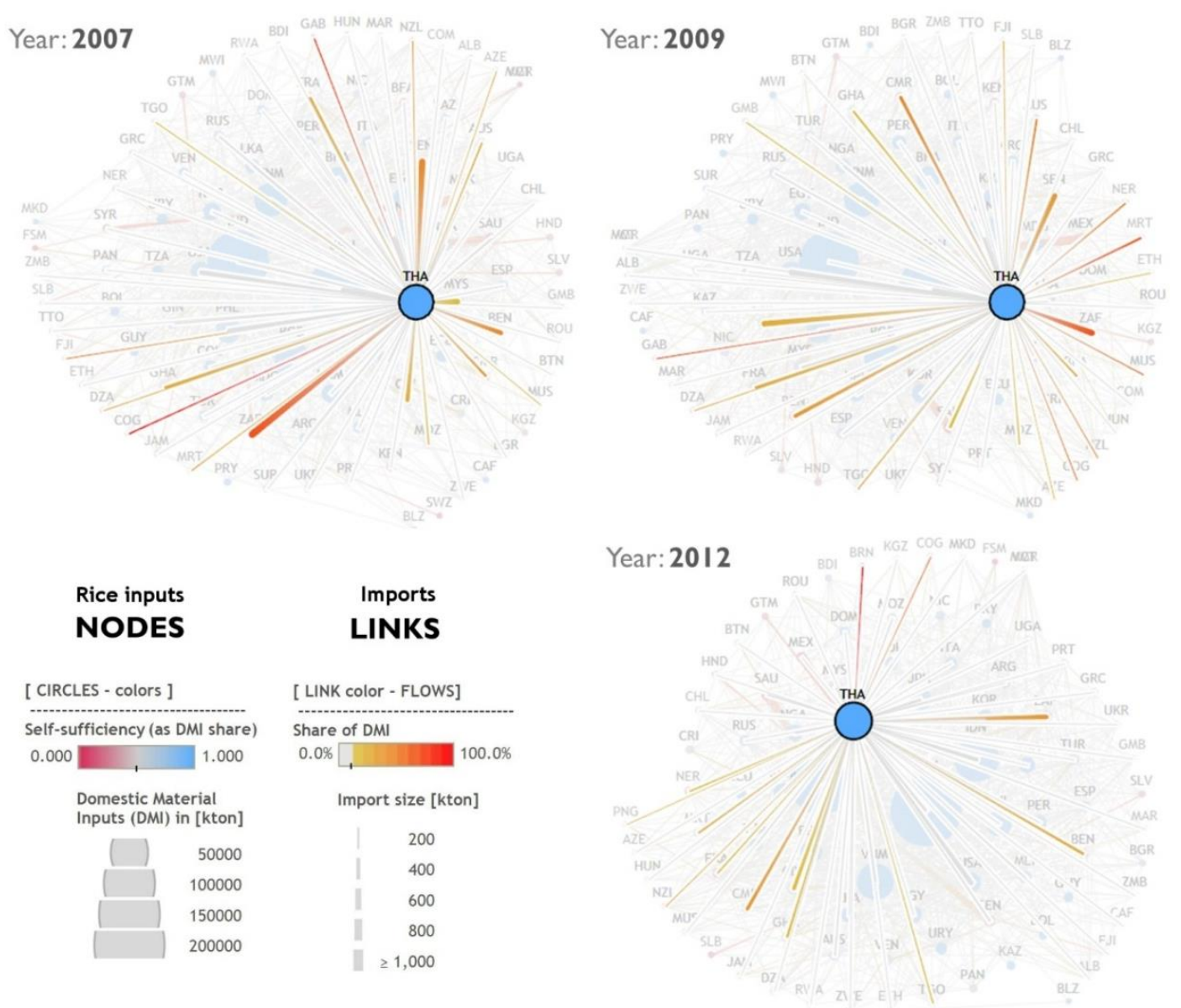

Figure 12. Rice trade and production focused around Thailand-highlights from 2007, 2009, and 2012. The trade relationships originating from Thailand have less red hues over time implying that Thai rice exports became significantly smaller shares of rice imports of their partners between 2007 and 2012.

\subsection{Future Prospects}

A report by International Institute for Sustainable Development on resilience and security of food networks [28] points out that resilience can be a property difficult to capture and assess in advance. This article shows that a combination of MFA data and visualization can in the least pinpoint potential hotspots vulnerable to export restrictions and show how the system responds to, recovers from and adapts to a disruption. However, the type of approach presented in this article can extend to a number of other adjacent interest areas.

First, the methodology can be readily applied to other products. Rice has been used as the case study due to its global importance as a staple food and a major disruption to its supply conveniently occurring in recent years. However, FAO keeps an extensive database of extraction (and consumption) of food items around the world. Most of the latter can be linked directly to traded goods monitored by the UN Comtrade, which started releasing data in three-month intervals, instead of yearly aggregates, enabling more timely analyses. Moreover, a more sophisticated approach could extend the scope to other material categories of MFA, such as fossil fuels, phosphate ores, or metals or more complex products; after accounting for the different stages of production and consumption.

Secondly, the data on production and trade of goods can be combined and remixed further with other resilience-relevant data, such as anticipated regional impacts of climate change or potential scenarios of major catastrophic events, whether it be droughts or pandemics wiping out a certain breed 
or variety of an agricultural product. Figure 13 offers an example of combining weather hazard with agricultural production data. Vast majority of rice production is concentrated in areas with significant risk of weather-induced damages. As the potential for climate change increases, so does the risk of another rice crisis - this time initiated by production shortage caused by a catastrophic climate event.

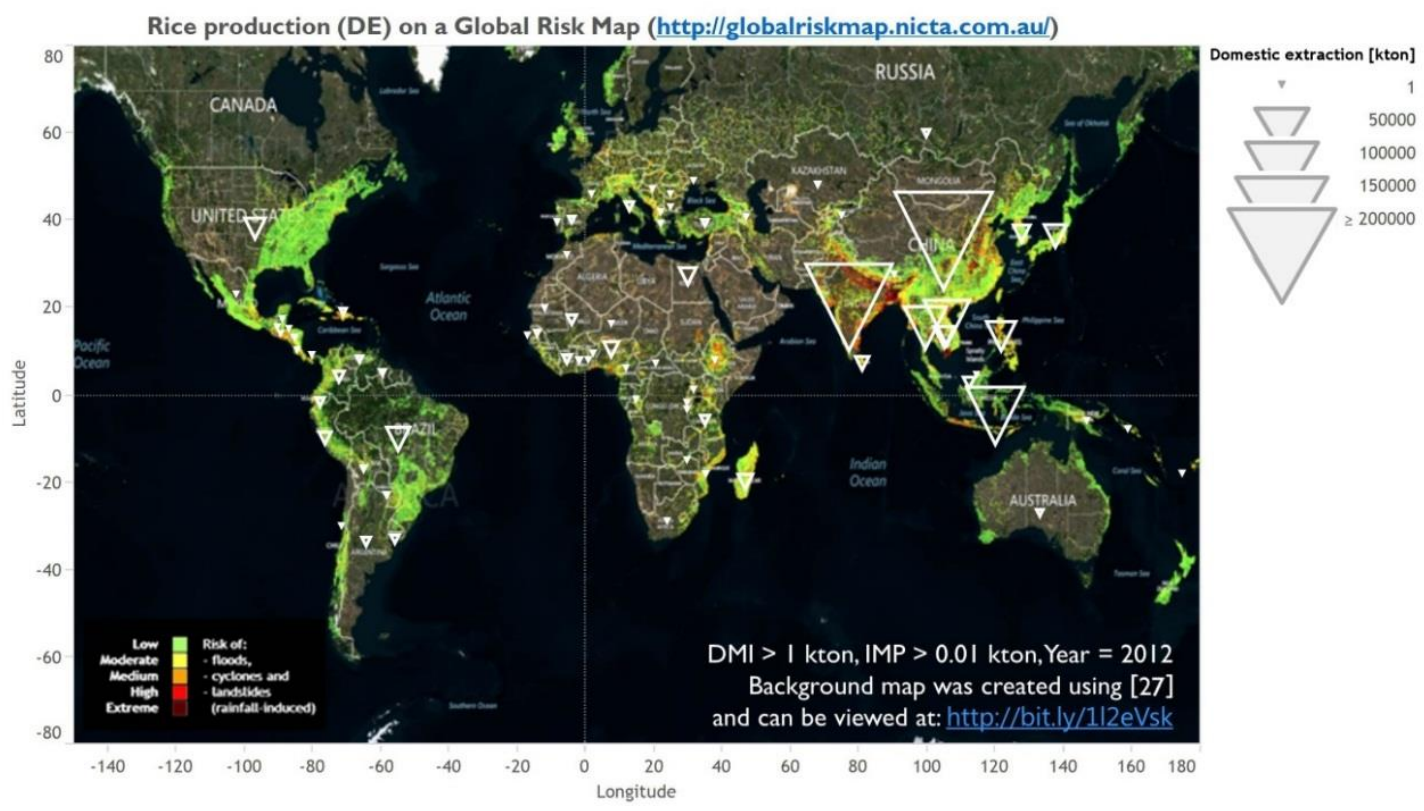

Figure 13. Rice production (FAO data) overlaid over a global risk map [27].

Finally, one can try to investigate the evolution of the networks (or price data) of actual, real-life systems instead of simulated models, using the data obtained from MFA or resilience studies such as this one. The focus on this article was on showing the benefits of visual explorations rather than generating new analytical results, but considering the success of the Observatory of Economic Complexity [29] in leveraging network science to both uncover new insights into development of economic structure and spark public interest in the topic, there is still much to be learned from all the information contained in the flows of materials.

The fact that visual communication elicits "more and better factual communication" [30] is by no means new - it can be dated back to the work of William Playfair in the 18th century. The difference nowadays lies in the ease with which one can transform large amounts of open access data into captivating visuals. Modern journalism and media have already started tapping into the potential of interactive, "data-driven stories", but science can also grow through delivering "explorable explanations" [31].

\section{Conclusions}

The method of applying HHI and self-sufficiency measures to material flows' data shows promise especially in investigating impacts of potential export restrictions. In a broader context, it also allows us to show the risk, and results, of organizational and structural lock-ins $[9,15]$ and an excessive drive towards efficiency in food supply networks. For rice, it means that resilience of smaller nations is becoming eroded by effects of scale and price factors, whereas the biggest producers are similar to colossi with feet of clay, because their consumption cannot be fulfilled by global trade in the case of an emergency.

While the gaps between different fields of science are gradually dissolving, there is still much room for improvement. As proven by the success of the Observatory of Economic Complexity, visual display of quantitative information plays crucial role in disseminating information and encouraging 
exploration; whereas transition to a graphical, context-rich approach, on top of interactive queries, allows capturing new insights which might have been elusive so far.

Acknowledgments: The authors would like to thank the anonymous reviewers and the editorial staff for a scrupulous, yet fast-paced review process.

Author Contributions: Michal Monit designed the research, compiled and analyzed the data, prepared the visuals, and drafted the manuscript. Michal Monit, André Pina, and Paulo Ferrão reviewed the results and wrote the paper.

Conflicts of Interest: The authors declare no conflict of interest.

\section{Appendix A}

Although material flow analysis and material flow accounting are not the same (the first term is broader and can incorporate a number of other approaches), in this article, both terms are used interchangeably and shortened to "MFA".

\section{Appendix B}

Most of the diagrams in this article are available as interactive visualizations at: http:/ / ricestudyvis.weebly.com (the first visualization based around basic terms and HHI, the second one focusing on link-node layouts and maps). Using the online visualization is it is possible to replicate the figures used in this study, with the exception of Figure 9. All the differences between the versions in this article and online had been a direct result of the scientific peer review process.

The visualizations have been constructed in Tableau Public 9.0 based on data from UN Comtrade and FAO processed using R language. Each of them is made available for download, which means that the underlying data can be extracted as well. Moreover, the rice data can be substituted and, provided the new data has a similar structure, the visualizations can be reused and repurposed.

\section{Appendix C}

Two of the major principles driving this article were transparency and encouraging exploration. Hence, the data has not been cleaned properly on purpose. That means that during exploration of the visualization one can experience firsthand some of the issues resulting from work with data. Among other things: Papua New Guinea (PNG) and Zimbabwe (ZWE) have some clearly erroneous entries, there are instances of some significant countries missing data (e.g., a year of extraction in Bangladesh), discontinuities occurring and problems combining data (e.g., each major organization lists different set of "countries", hence ISO3 codes sometimes do not agree either). Following the same reasoning, the data has been left in a close-to-raw state, following a few basic join operations and filtering has only been used to get a better look into the data and not to remove the outliers.

\section{Appendix D}

The node-link diagrams have been inspired by the following article: http:/ /www.clearlyandsimply.com/ clearly_and_simply/2012/12/build-network-graphs-in-tableau.html and the layouts are based on a phyllotaxis spiral.

\section{References}

1. Slayton, T.; Slayton, B.T. Rice Crisis Forensics: How Asian Governments Carelessly Set the World Rice Market on Fire; CGD Working Paper Number 163; Center for Global Development: Washington, DC, USA, 2009.

2. Aker, J.; Block, S.; Ramachandran, V.; Timmer, C.P. West African experience with the world rice crisis, 2007-2008. Cent. Glob. Dev. 2011. [CrossRef]

3. Bringezu, S.; Schütz, H.; Moll, S. Rationale for and interpretation of economy-wide materials flow analysis and derived indicators. J. Ind. Ecol. 2003, 7, 43-64. [CrossRef] 
4. Fischer-Kowalski, M.; Hüttler, W. Society's metabolism. the intellectual history of material flow analysis, part II: 1970-1998. J. Ind. Ecol. 1998, 2, 107-137. [CrossRef]

5. Eurostat. Economy-Wide Material Flow Accounts and Derived Indicators: A Methodological Guide; Office for Official Publications of the European Communities: Luxembourg, Luxembourg, 2001.

6. Fischer-Kowalski, M.; Krausmann, F.; Giljum, S.; Lutter, S.; Mayer, A.; Bringezu, S.; Moriguchi, Y.; Schütz, H.; Schandl, H.; Weisz, H. Methodology and indicators of economy-wide material flow accounting: State of the art and reliability across sources. J. Ind. Ecol. 2011, 15, 855-876. [CrossRef]

7. Eurostat. Economy-Wide Material Flow Accounts (EW-MFA): Compilation Guide 2013; Statistical Office of the European Communities: Luxembourg, Luxembourg, 2013.

8. Gerst, M.D.; Graedel, T.E. In-use stocks of metals: Status and implications. Environ. Sci. Technol. 2008, 42, 7038-7045. [CrossRef] [PubMed]

9. Haberl, H.; Fischer-Kowalski, M.; Krausmann, F.; Weisz, H.; Winiwarter, V. Progress towards sustainability? What the conceptual framework of material and energy flow accounting (MEFA) can offer. Land Use Policy 2004, 21, 199-213. [CrossRef]

10. Janssen, M.A.; Schoon, M.L.; Ke, W.; Börner, K. Scholarly networks on resilience, vulnerability and adaptation within the human dimensions of global environmental change. Glob. Environ. Chang. 2006, 16, 240-252. [CrossRef]

11. Holling, C.S. Resilience and stability of ecological systems. Annu. Rev. Ecol. Syst. 1973, 4, 1-23. [CrossRef]

12. Holling, C.S. Engineering resilience versus ecological resilience. In Engineering within Ecological Constraints; Schulze, P., Ed.; National Academy: Washington, DC, USA, 1996; pp. 31-44.

13. Laprie, J.-C. From Dependability to Resilience. In Proceedings of the 38th Annual IEEE/IFIP International Conference on Dependable Systems and Networks, Anchorage, AK, USA, 24-27 June 2008.

14. The Ellen MacArthur Foundation. Efficiency vs. Effectiveness. Available online: http://www. ellenmacarthurfoundation.org/business/toolkit/toolkit-efficiency-vs-effectiveness (accessed on 8 June 2015).

15. Zhu, J.; Ruth, M. Exploring the resilience of industrial ecosystems. J. Environ. Manag. 2013, 122, 65-75. [CrossRef] [PubMed]

16. Vespignani, A. Complex networks: The fragility of interdependency. Nature 2010, 464, 984-985. [CrossRef] [PubMed]

17. Adger, W.N. Vulnerability. Glob. Environ. Chang. 2006, 16, 268-281. [CrossRef]

18. Gallopín, G.C. Linkages between vulnerability, resilience, and adaptive capacity. Glob. Environ. Chang. 2006, 16, 293-303. [CrossRef]

19. Manzo, K. Imaging vulnerability: The iconography of climate change. Area 2010, 42, 96-107. [CrossRef]

20. Opach, T.; Rød, J.K. Cartographic visualization of vulnerability to natural hazards. Cartographica 2013, 48, 113-125. [CrossRef]

21. USAID. FEWS-Famine Early Warning Systems Network. Available online: http://www.fews.net/ (accessed on 15 August 2015).

22. Folke, C.; Carpenter, S.R.; Walker, B.; Scheffer, M.; Chapin, T.; Rockström, J. Resilience thinking: Integrating resilience, adaptability and transformability. Ecol. Soc. 2010, 15, 20.

23. Food and Agriculture Organization of the United Nations-Statistical Devision. FAOSTAT Database. Available online: http:/ / faostat3.fao.org/download/Q/QC/E (accessed on 18 May 2015).

24. The UN Comtrade data extraction API. Available online: http://comtrade.un.org/data/doc/api/ (accessed on 18 May 2015).

25. Dittrich, M.; Giljum, S.; Lutter, S. Green Economies around the World? Implications of Resource Use for Development and the Environment; SERI: Vienna, Austria, 2012.

26. R: A Language and Environment for Statistical Computing; $\mathrm{R}$ Development Core Team; $\mathrm{R}$ Foundation for Statistical Computing: Vienna, Austria, 2008.

27. NICTA. Global Risk Map. Available online: http://globalriskmap.nicta.com.au/ (accessed on 25 October 2015).

28. IISD. Climate Resilience and Food Security A Framework for Planning and Monitoring. Available online: http:/ / www.fao.org/fsnforum/sites/default/files/resources/CREFSCA Paper June 2013 EN(FINAL).pdf (accessed on 1 August 2015). 
29. Simoes, A.J.G.; Hidalgo, C.A. The Economic Complexity Observatory: An Analytical Tool for Understanding the Dynamics of Economic Development. In Scalable Integration of Analytics and Visualization; Association for the Advancement of Artificial Intelligence: San Francisco, CA, USA, 2011.

30. Williard, C.B. Graphic Presentation; Brinton Associates: New York City, NY, USA, 1939.

31. Victor, B. Explorable Explanations. Available online: http://worrydream.com/ExplorableExplanations/ (accessed on 29 September 2015).

(C) 2016 by the authors; licensee MDPI, Basel, Switzerland. This article is an open access article distributed under the terms and conditions of the Creative Commons by Attribution (CC-BY) license (http:/ / creativecommons.org/licenses/by/4.0/). 